\title{
Eden receives the 2015 Georg Wüst Prize
}

\author{
Jörg-Olaf Wolff ${ }^{1}$
}

Received: 19 April 2015 / Accepted: 21 April 2015 / Published online: 19 May 2015

(C) Springer-Verlag Berlin Heidelberg 2015

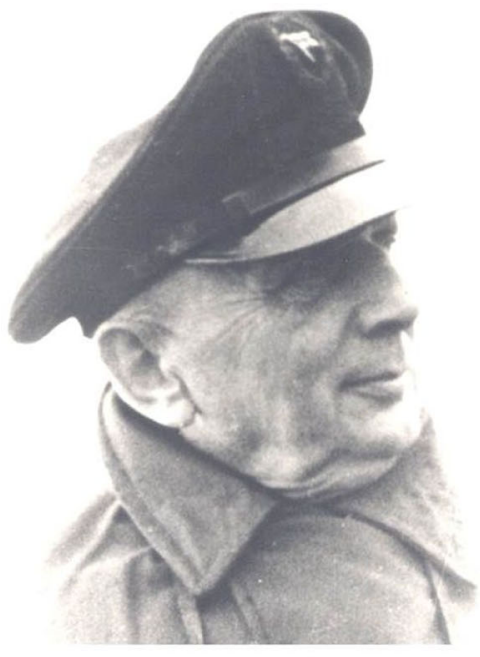

Prof. Dr. Georg Wüst

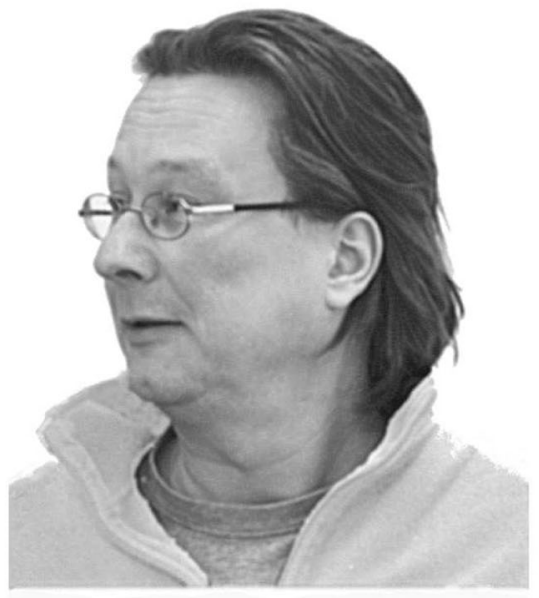

Prof. Dr. Carsten Eden
Prof. Dr. Carsten Eden received the Georg Wüst Prize 2015 at the European Geophysical Union (EGU) General Assembly in Vienna, Austria, April 2015. This biannual prize is awarded for outstanding contributions to the general field of oceanography and is sponsored by the German Society

Responsible Editor: Jörg-Olaf Wolff

Jörg-Olaf Wolff

wolff@icbm.de

1 Department of Physical Oceanography (Theory), Institute for Chemistry and Biology of the Marine Environment (ICBM), Carl von Ossietzky Universität Oldenburg, Carl-von-Ossietzky-Str. 9-11, 26111 Oldenburg, Germany for Marine Research and Ocean Dynamics. The following is a transcript of the citation by Profs. Koch and Wolff and the response by Prof. Eden.

\section{Citation by Prof. Koch:}

It is our great honour and distinct pleasure to announce Prof. Carsten Eden (Institute of Oceanography, University of Hamburg) as this years recipient of the Georg Wüst Prize. The biannual award is presented by the German Society for Marine Research (Deutsche Gesellschaft für Meeresforschung, DGM) and kindly supported by the publisher Springer and the Journal Ocean Dynamics.

The German Society for Marine Research with its 450 members wants to support communication and networking between scientists in ocean research. Wherever possible, we seek to highlight and honour outstanding 
scientific contributions in ocean research. The Georg Wüst Prize honours excellent mid-career scientists. By that, the prize fills a gap between numerous awards for early career scientists and lifetime achievements.

The inaugural presentation of the Georg Wüst Prize was in 2005 in Vienna at the EGU general assembly. Arnold Gordon and Jörg Wolff presented the award to Stephen Rintoul. In the following years, an illustrious group of marine researchers was awarded: Eberhard Fahrbach (2007), Karen Heywood (2009), Andreas Oschlies (2011), Gregory Johnson (2013) and now Carsten Eden.

Georg Wüst's career focussed on the deep currents in the Atlantic. He was the first German researcher who received a habilitation in Marine Science. After World War II, Wüst became director of the Institute for Marine Sciences in Kiel. In June, he would have celebrated his 125th birthday. Despite his outstanding career, there was one thing Wüst was not capable of: he could not predict the future - as most of us cannot, of course. In that sense, Carsten Eden's work is remarkable because his research helps to improve the reliability of predictions made using ocean models.

Congratulations Carsten!

Prof. Dr. Boris Koch

President German Society for Marine Research

\section{Citation by Prof. Wolff:}

As Chief Editor of Ocean Dynamics, it is my honor and distinct pleasure to present the Georg Wüst Prize 2015 to Prof. Eden. Before presenting the achievements of Carsten Eden, I first quote from Arnold Gordon's statement at the 2005 ceremony concerning Georg Wüst's achievements.

Georg Wüst, born 15 June 1890, brought descriptive oceanography into the modern era. Through a careful analysis of each hard-won observational data point that passed his meticulous quality control procedures, he probed into the secrets of the ocean, contributing to several research areas. He is best known for his Atlantic Ocean studies, where with great insight and skill he combined water mass analysis by means of the temperature-salinity relationship and the core method, with the dynamic approach of geostrophic balance, to reveal the nature of the deep Atlantic's stratification and circulation.

Coming now to Carsten Eden, I quote from the nomination letter:

Carsten Eden can look back on a long and successful career as a theoretical oceanographer. He has dealt with various aspects of the theory of the ocean circulation in the climate system, in which he not only considered physical aspects but also biogeochemical issues and so proved his versatility. In addition to a lively publication record in recognized journals he has recently co-authored an extensive text book on the fundamentals of theoretical oceanography (Olbers et al. 2012) which was well received by the community. His most important internationally recognized work concerns the role of meso-scale eddies in the ocean, their parameterization in largescale models, and the response of the North Atlantic to stochastic excitations by the North Atlantic Oscillation. His papers on the role of length scales and rotational components of eddy fluxes are regarded as particularly innovative. Valuable new and practical parametrizations of isopycnic mixing for the mean oceanic circulation evolved from these ideas. In recent years, he has devoted himself to the parameterization of internal wave processes in order to develop models of diapycnic mixing. It is noteworthy that these models allow for the first time the parameterisation of the energy cascade from the large-scale circulation, via eddy and wave fields, to small-scale turbulence, and then the feedback to the large-scale circulation via diapycnal mixing, and that all this is done in a physically consistent way. Thus, the first energetically consistent circulation model of the ocean was born.

As a theoretician, Carsten Eden used for his research topics a wide range of simple models to complex high-resolution circulation models. He has developed simplified ocean models for wind-driven topographically affected currents and low-frequency waves and for the zonally averaged overturning circulation. This makes his research very original and successful.

Prof. Eden is an internationally recognized scientist for theoretical and numerical ocean research and a well-established expert in the relevant meetings and committees. With the election of a theoretical oceanographer the prize committee could put a clear sign that today's oceanography requires in addition to the field work also theoretical and numerical research and only this combination can make our science successful.

The following remark from Arnold Gordon in the citation 2 years ago clearly demonstrates Wüst's vision of progress in ocean sciences:

Georg Wüst (1964) stated that oceanographic progress depends directly on the observations from the great 
ocean expeditions, with advances hinged on technology, improvement of instrumentation, and data analysis closely linked to the development of new theoretical concepts.

The prize consists of a 3-D laser-engraved picture of the old meteor in a glass block, a prize certificate, an honorary lifetime membership of the German Society of Marine Research, and a prize money of $€ 1500$.

Congratulations Carsten!

Prof. Dr. Jörg-Olaf Wolff

Chief Editor, Ocean Dynamics

\section{Response by Prof. Eden:}

I would like to thank Jörg-Olaf Wolff and Boris Koch for honoring me with the Georg Wüst Prize at the General Assembly of the EGU 2015 in Vienna and I would also like to thank the DGM for awarding the prize and the journal Ocean Dynamics by Springer for sponsoring the prize.

When Jörg-Olaf Wolff informed me last December about the nomination, I was thinking about my personal relationship to Georg Wüst. I did not have the chance to meet Georg Wüst in person, but there is in fact a rather direct relation: I was educated as a physical oceanographer at the (former) Institut für Meereskunde in Kiel, which was reestablished by Georg Wüst after 1945 and led by him for many years. One of his successors as director of that institute was Jürgen Willebrand, the supervisor of my Diploma, $\mathrm{PhD}$ and Habilitation thesis. Jürgen Willebrand together with Richard Greatbatch and Dirk Olbers have been and still are my most influential teachers and mentors for which I would like to thank them.

During my time in Kiel, I was exposed to Jürgen Willebrand's thorough and serious way to derive and understand the physics of the ocean starting from first principles. Prepared with this rather "German way" of doing science, I was later also exposed to a different way of doing science by Richard Greatbatch during my time as a postdoctoral researcher at Dalhousie University in Halifax, Canada. There, I had the opportunity to benefit from Richard's more practical or "British way" to approach problems, which often starts with knowing the answer and working backward instead of starting at the beginning and doing it the "German way". I am grateful that I had the opportunity to benefit from both ways and I believe that a combination of both is the "best way" for me.

I first got in touch with Dirk Olbers, a close friend of Jürgen Willebrand, as he once called me during my $\mathrm{PhD}$ studies when I was working with the barotropic vorticity equation and told me that I am doing this wrong and that he knows how to do it better. He did indeed, and the result of this collaboration is the BARBI model. Since then, we developed and are still working on several other models and concepts with similar colourful names, e.g. IDEMIX. The collaboration with Jürgen Willebrand, Richard Greatbatch and Dirk Olbers-and the collaboration with many other colleagues and students from which I benefited-is recorded by many papers from the last years which cannot all be named here. But I want to take the opportunity to name the textbook "Ocean Dynamics" by Jürgen Willebrand, Dirk Olbers and myself, having the same title as the famous journal and which was also edited by Springer.

Studying physical oceanography in Kiel, I was exposed to one of the most important contributions by Georg Wüst. This contribution was also covered by the textbook "Allgemeine Meereskunde" by Dietrich, Kalle, Krauss and Siedler, which all have been collaborators or successors of Georg Wüst in Kiel. As a student in Kiel, I was supposed to read that book and I was fascinated about the nice colour plates showing the water masses distributions in the Atlantic, Pacific and Indian Ocean, since they very clearly display the meridional circulation in the oceans, a feature which is today called meridional overturning circulation or MOC and which is still not fully understood and a topic of intense scientific debate. These plates have been based on the earlier work by Wüst (1978). I recently read that article again, which is illustrated with even more and beautiful color plates of sections and isosurfaces of temperature, salinity and oxygen. In this article, Georg Wüst indicated and discussed almost a hundred years ago what we now call the MOC, based on the water mass distribution in the Atlantic Ocean measured by the Meteor expedition which he also joined. I can only hope that the results of my work and also our present work in physical oceanography in general will last and will be of benefit for a similar long time span as Georg Wüst's work.

\section{References}

Olbers D, Willebrand J, Eden C (2012) Ocean Dynamics. Springer, Heidelberg, 704 pp. doi:10.1007/978-3-642-23449-1

Wüst G (1978) Schichtung und Zirkulation des Atlantischen Ozeans: Die Stratosphäre. In: Emery WJ (ed) Wissenschaftliche Ergebnisse der Deutschen Atlantischen Expedition auf dem Forschungsund Vermessungsschiff "Meteor" 1925-1927. Vol. 6, first part, 2, Berlin, $180 \mathrm{pp}$. English translation. The Stratosphere of the Atlantic Ocean. Amerind, New Delhi, 112 pp.

Wüst G (1964) The major deep-sea expeditions and research vessels 1873-1960, a contribution to the history of oceanography. Prog Oceanogr 2:1-52. doi:10.1016/0079-6611(64)90002-3 